\title{
Production of Greek vowels by hearing-impaired children
}

\author{
Elina Nirgianaki ${ }^{1,2}$, Maria Bitzanaki ${ }^{2}$ \\ ${ }^{1}$ Department of Speech and Language Therapy, University of Peloponnese, Greece \\ ${ }^{2}$ Department of Speech and Language Therapy, Metropolitan College, Greece \\ https://doi.org/10.36505/ExLing-2020/11/0036/000451
}

\begin{abstract}
The present study investigates the acoustic characteristics of Greek vowels produced by hearing-impaired children with profound prelingual hearing loss and cochlear implants. The results revealed a significant difference between vowels produced by hearingimpaired children and those produced by normal-hearing ones in terms of duration. Stressed vowels were significantly longer than non-stressed for both groups, while F0, F1 and F2 did not differ significantly between the two groups for any vowel, with the exception of $/ \mathrm{a} /$, which had significantly higher $\mathrm{F} 1$ when produced by hearingimpaired children. Acoustic vowel spaces were similar for the two groups but shifted towards higher frequencies in the low-high dimension and somehow reduced in the front-back dimension for the hearing-impaired group.
\end{abstract}

Keywords: hearing impairment, children, Greek vowels, duration, formants

\section{Introduction}

Hearing-impaired speech is characterized by deviations both in segmental and suprasegmental level that often affect intelligibility and communication. As far as the segmental level is concerned, several deviations have been observed not only in the production of consonants, but also of vowels, despite the fact that their production is considered much easier. Among others, vowel substitutions and neutralization have been frequently reported in the speech of hearingimpaired individuals due to limited auditory feedback (e.g. Ryalls et al. 2003).

Acoustically, vowels produced by hearing-impaired speakers have been revealed to cover more restricted formant space, with more overlaps than the ones produced by normal-hearing speakers (e.g. Ryalls et al. 2003). Moreover, excessive duration is among the suprasegmental errors that have been reported in several studies (e.g. Hasanvand, et al. 2017) for both adults and children with hearing impairment. However, the results regarding the duration in hearingimpaired children's speech remain contradictory, as there are also studies reporting no difference in comparison to normal-hearing children's speech (Ghayedlou et al. 2020).

With regards to the production of Greek vowels, Nicolaidis \& Sfakianaki $(2007,2016)$ have found significant differences between vowels produced by normal-hearing and hearing-impaired adults, such as prolonged duration and reduced vowel space for the latter group. To our knowledge there are no

ExLing 2020: Proceedings of $11^{\text {th }}$ International Conference of Experimental Linguistics, 12-14 October 2020, Athens, Greece 
studies on vowel acoustic parameters of Greek hearing-impaired children's speech in the literature.

Along this line of research, the present study aims at investigating the acoustic characteristics of Greek vowels, and particularly, duration, F0, F1 and F2, produced by hearing-impaired children by comparing them with those produced by normal-hearing children.

\section{Method}

The speech material consisted of ten real CVCV words produced within the carrier phrase /'ipe _ 'pali/ ("He/She said _ again"). The first syllable was either stressed or non-stressed, containing the target vowel which varied among the five Greek vowels, while the preceding and following consonants were voiceless stops. Three hearing-impaired children aged 8-12 years old with profound prelingual hearing loss and cochlear implants and four normalhearing peers produced the speech material three times at a normal tempo in a quiet room. A consent form was signed by the parents/carers. Duration, as well as F0, F1 and F2 (in the middle of each vowel) were measured in Praat software (Boersma \& Weenink 2019). SPSS (v26) was used for data statistical analysis.

\section{Results}

Table 1 shows the mean values of duration, F0, F1 and F2 per vowel, for normal-hearing and hearing-impaired children, averaged across stressed and non-stressed vowels as well as across boys and girls.

Table 1. Mean duration (ms), F0, F1 and F2 (Hz) values per vowel for normalhearing $(\mathrm{NH})$ and hearing-impaired $(\mathrm{HI})$ children.

\begin{tabular}{|l|l|l|l|l|l|l|l|l|}
\hline \multirow{2}{*}{ Vowels } & \multicolumn{2}{|l|}{ Duration } & F0 & F1 & F2 & \\
\cline { 2 - 9 } & NH & HI & NH & HI & NH & HI & NH & HI \\
\hline $\mathrm{i}$ & 64 & 167 & 257 & 262 & 401 & 408 & 2748 & 2618 \\
\hline $\mathrm{e}$ & 84 & 166 & 243 & 247 & 667 & 615 & 2023 & 2035 \\
\hline $\mathrm{a}$ & 110 & 173 & 255 & 244 & 832 & 931 & 1512 & 1551 \\
\hline $\mathrm{o}$ & 104 & 174 & 241 & 260 & 621 & 591 & 1265 & 1400 \\
\hline $\mathrm{u}$ & 73 & 143 & 235 & 255 & 438 & 393 & 930 & 951 \\
\hline
\end{tabular}

A 4-way Anova (group $\mathrm{x}$ gender $\mathrm{x}$ stress $\mathrm{x}$ vowel) for each one of the dependent variables revealed a significant difference between vowels produced by hearing-impaired children and those produced by normal-hearing ones in terms of duration $[\mathrm{F}(1,30)=44.207, \mathrm{p}<0,0001]$. Subsequent t-tests per vowel revealed significant differences for all vowels (marginally for $/ a /$ ). Stressed vowels were significantly longer than non-stressed for both normal-hearing $[\mathrm{t}(38)=-5.061, \mathrm{p}<0.0001]$ and hearing-impaired children $[\mathrm{t}(28)=-4.055$, $\mathrm{p}<0.0001$ ] (see Figures 1, 2). 


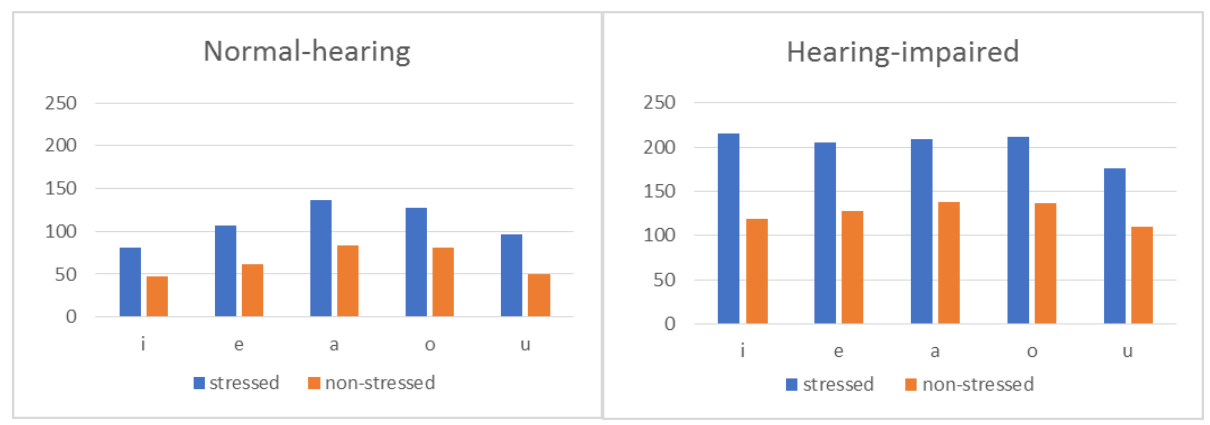

Figures 1, 2. The duration of Greek vowels for normal-hearing and hearingimpaired children in stressed and non-stressed condition, respectively.

F0, F1 and F2 did not differ significantly between the two groups for any vowel, except for $/ \mathrm{a} /$, which exhibited significantly higher F1 when produced by hearing-impaired children $(\mathrm{t}(12)=-2.680, \mathrm{p}<0.05)$.

The main effect of vowel on $F 1 \quad[F(4,30)=41,737, p<0.0001]$ and $F 2$ $[\mathrm{F}(4,30)=136,949, \mathrm{p}<0.0001]$, as well as subsequent post-hoc tests, indicated significantly distinguished vowel categories for the two groups in terms of both the low-high and the front-back dimension, respectively. In total, the acoustic space of hearing-impaired children is similar with the one of normal-hearing children but shifted towards higher frequencies in the low-high dimension and somehow reduced in the front-back dimension (Figure 3).

A main effect of gender was observed on $\mathrm{F} 0[\mathrm{~F}(1,27)=8,808, \mathrm{p}<0.05]$, with boys having significantly higher mean F0 than girls (256 vs. $224 \mathrm{~Hz}$ ).

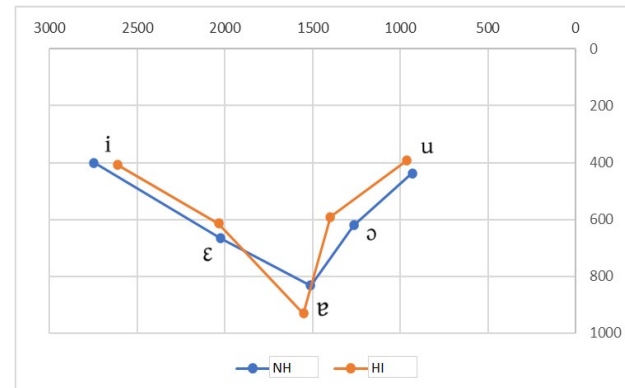

Figure 3. The acoustic spaces of Greek vowels as produced by normal-hearing $(\mathrm{NH})$ and hearing-impaired (HI) children.

\section{Discussion and conclusions}

Overall, the results indicate significant temporal differences in vowel production between normal-hearing and hearing-impaired children and few differences in vowel acoustic spaces. 
In terms of duration, vowels produced by hearing-impaired children were significantly prolonged, as previously reported for the English language too (Vandam et al. 2011). Vowels produced by normal-hearing children exhibited identical temporal hierarchical structure with those produced by both normalhearing (Fourakis et al. 1999) and hearing-impaired adults (Nicolaidis \& Sfakianaki, 2007), i.e. $\mathrm{i}<\mathrm{u}<\mathrm{e}<\mathrm{O}<\mathrm{a}$; while, for hearing-impaired children the order was $\mathrm{u}<\mathrm{e}, \mathrm{i}<\mathrm{a}, \mathrm{O}$, with all vowels having almost the same duration except for the shortest $/ \mathrm{u} /$. Stressed vowels were significantly longer than nonstressed for both groups, indicating that they both use the temporal parameters similarly to normal-hearing and hearing-impaired adults (Nicolaidis \& Sfakianaki, 2007), in order to denote the effect of stress.

Regarding formant frequencies, vowel categories are clearly distinguished for all children. Compared to normal-hearing, hearing-impaired children show: (1) higher F1 for the low vowel, and (2) somehow reduced space in the front-back dimension; which may be related to the increased and reduced visibility of articulatory gestures forming the vowel constriction along the low-high and front-back axes of the vocal tract, respectively.

\section{References}

Boersma, P., Weenink, D. 2019. Praat: doing phonetics by computer [Computer program]. Version 6.0.50.

Fourakis, M., Botinis, A., Katsaiti, M. 1999. Acoustic characteristics of Greek vowels. Phonetica, January, vol.56, pp. 28-43.

Ghayedlou, L., Ahmadi, A., Ghorbani, A., Torabinezhad, F., Keyani, M.R., Hashemi, S.B. 2020. Vowel duration measurement in shool-age children with cochlear implant. Int J of Pediatric Otorhinolaryngology, September, 136, pp.110-142.

Hasanvand, M., Torabinezhad, F., Abolghasemi, J., Eslami, M. 2018. A comparison of speech duration in cochlear implant and normal hearing elementary school students in the imitation and reading tasks. Func Disabil J, 1(1):21-30.

Nicolaidis, K., Sfakianaki, A. 2007. An acoustic analysis of vowels produced by Greek speakers with hearing impairment. ICPhS, August, vol. XVI, pp. 1969-1972.

Nicolaidis, K. \& Sfakianaki, A. 2016. Acoustic characteristics of vowels produced by Greek intelligible speakers with profound hearing impairment II: The influence of stress and context. Int J Speech-Language Pathology, April, vol.18, no.4, pp. 1-14.

Ryalls, J., Larouche A., Giroux, F. 2003. Acoustic comparison of CV syllables in French-speaking children with normal hearing, moderate-to-severe and profound hearing impairment. Journal of Multilingual Communication Disorders 1, 99-114.

Vandam, M., Ide-Helvie, D., Moeller, M. P. 2011. Point vowel duration in children with hearing aids and cochlear implants at 4 and 5 years of age. Journal of Clinical Linguistics and Phonetics, August, vol.25, no.8, pp. 689-704. 